Jurnal

Belo
Volume 6 Nomor 1 Agustus 2020 - Januari 2021

DOI: https://doi.org/10.30598/belovol6issue1page195-207

p-ISSN : 2460-6820 | e-ISSN : 2686-5920

Penerbit : Fakultas Hukum Universitas Pattimura

\title{
Perlindungan Anak Yang Menjadi Pemakai Narkotika Dengan Rehabilitasi Kesehatan
}

\author{
Jacob Hattu ${ }^{1, *}$, Astuti Nur Fadillah ${ }^{2}$ \\ ${ }^{12}$ Fakultas Hukum Universitas Pattimura \\ $\underline{\text { hattuyopie@gmail.com }}{ }^{1}$ astutifadillah@gmail.com $^{2}$ \\ * Corespondence Author
}

\begin{abstract}
Abstrak
Penggunaan Narkotika oleh anak berdampak pada perkembangan dirinya, apalagi sampai mengalami ketergantungan, untuk itu anak yang menggunakan Narkotika. Tujuan penulisan ini untuk menemukan bentuk perlindungan hukum dengan pemberiaan rehabilitasi kesahatan terhadap anak sesuai dengan Undang-Undang Perlindungan Anak, Undang-Undang Sistem Peradilan Anak dan Undang-Undang Narkotika. Metode yang digunakan adalah Yuridis Normatif. Anak adalah aset bangsa, karena aset bangsa maka anak harus dilindungi hak-haknya baik dalam perlindungan sosial maupun perlindungan hukum, anak yang sudah menjadi pemakai atau pecandu harus harus diberikan rehabilitasi, wajib diberikan rehabilitasi, namun dalam Putusan Nomor 25/Pid.Sus-Anak/2020/PN Amb, anak ditempatkan bukan pada lembaga rehabilitasi, untuk itu harus dilakukan upaya hukum atas putusan tersebut agar hakim Pengadilan Tinggi dapat menetapkan dalam amar putusan agar kedua anak pelaku tindak pidana narkotika ditempatkan pada lembaga rehabilitasi yang ditunjuk sesuai dengan Pasal 103 Undang-Undang Narkotika.
\end{abstract}

\section{Kata Kunci : Perlindungan, Anak, Narkotika}


Naskah dikirim: 20 Januari 2021|Direvisi: 15 Februari 2021|Diterbitkan: 28 Februari 2021

\begin{abstract}
The use of Narcotics by children has an impact on their own development, especially until they experience dependence, for that children use Narcotics. The purpose of this study was to find a form of legal protection by providing health rehabilitation for children in accordance with the Child Protection Law, the Juvenile Justice System Law and the Narcotics Law. The method used is Normative Juridical. Children are the assets of the nation, because the assets of the nation, the rights of children must be protected both in social protection and legal protection, children who are already users or addicts must be given rehabilitation, must be given rehabilitation, but in Decision Number 25 / Pid.SusAnak / 2020 / PN Amb, the child being served is not in a rehabilitation institution, for this reason, legal remedies must be made against the decision so that the High Court judge can be determined in the ruling so that the two narcotics crimes are placed in the designated rehabilitation institution in accordance with Article 103 of the Law. Narcotics Act.
\end{abstract}

\title{
Keywords: Protection, Children, Narcotics
}

\section{Pendahuluan}

Perlindungan Anak disebutkan "Setiap anak berhak untuk dapat hidup, tumbuh, berkembang, dan berpartisipasi secara wajar sesuai dengan harkat, martabat kemanusiaan, serta mendapat perlindungan dari kekerasan dan diskriminasi”, anak masih punya masa depan yang Panjang, jika dia terlibat dalam tindak pidana kita tidak bisa menempatkan anak sebagai pelaku kejahatan namun harus menempatkan anak sebagai korban dari tindak pidana tersebut. Melindungi anak ialah melindungi manusia, dan membangun manusia seutuh mungkin. Hakekat Pembangunan Nasional ialah pembangunan manusia Indonesia seutuhnya yang berbudi luhur. Mengabaikan masalah perlindungan anak berarti tidak akan memantapkan pembangunan nasional. Akibat tidak adanya perlindungan anak akan 
menimbulkan berbagai permasalahan sosial yang dapat mengganggu penegakan hukum, ketertiban, keamanan, dan pembangunan nasional. Maka, ini berarti bahwa perlindungan anak harus diusahakan apabila kita ingin mengusahakan pembangunan nasional. ${ }^{1}$

Perlindungan hukum bagi anak yang berhadapan dengan hukum dapat diartikan sebagai upaya Perlindungan hukum terhadap berbagai kebebasan dan hak asasi anak. Jadi masalah Perlindungan hukum bagi anak mencakup hal yang sangat luas. Undang-Undang Nomor 11 Tahun 2012 tentang Sistem Peradilan Pidana Anak menegaskan bahwa penuntut umum anak wajib mengupayakan diversi apabila kasus tersebut memenuhi syarat-syarat untuk dilakukannya diversi. Terlepas apakah sudah sesuai antara pasal-pasal yang mengatur tentang diversi di dalam Undang-Undang Nomor 11 Tahun 2012 tentang Sistem Peradilan Pidana Anak dengan penerapannya selama ini, sangat penting untuk menyelesaikan kasus tindak pidana yang melibatkan anak. ${ }^{2}$

Undang-Undang Nomor 11 Tahun 2012 tentang Sistem Peradilan Anak dan Undang-Undang Nomor 8 Tahun 1981 tentang Hukum Acara Pidana. Mengenai pengertian dan batasan umur anak telah dijabarkan dalam beberapa peraturan perundangan-undangan yang berlaku adalah sebagai berikut : 1) Pengertian anak menurut Kitab Undang-Undang Hukum Pidana (KUHP) anak dalam hukum pidana diletakkan dalam pengertian seorang anak yang belum dewasa, sebagai orang yang mempunyai hak-hak khusus dan perlu mendapatkan Perlindungan menurut ketentuan hukum yang berlaku. 2) Pengertian anak menurut Undang-Undang Nomor 3 Tahun 1997 yang dimaksud dengan anak dalam Undang-Undang ini yaitu orang yang dalam perkara anak nakal telah mencapai umur 8 (delapan) tahun tetapi belum mencapai umur 18 (delapan belas) tahun dan belum pernah meningkah. 3) Pengertian anak menurut Undang-Undang Nomor 11 Tahun 2012 tentang Sistem Peradilan Pidana Anak, pengertian anak menurut Undang-undang ini yang disebut

\footnotetext{
${ }^{1}$ Romli Atmasasmita, Peradilan Anak di Indonesia, Bandung: Mandar Maju, 1997, hal. 166.

2 Satino, Sulastri, \& Yuli W, Y. (2020). Perlindungan Hukum Terhadap Anak Yang Melakukan Tindak Pidana Melalui Diversi Berdasarkan Sistem Peradilan Pidana Anak. Esensi Hukum, 2(1), 15-27. https://doi.org/10.35586/esensihukum.v2i1.26
} 
anak yang telah berumur 12 (dua belas) tahun tetapi belum berumur 18 (delapan belas) tahun. ${ }^{3}$

Narkotika jika disalahgunakan sagat berbahaya bagi pemakainnya karena menimbulkan ketergantungan, ${ }^{4}$ Anak merupakan salah satu korban dari peredaran narkotika yang tidak memandang jenis kulis, ras, agama bahkan umur seseorang, anak sering sekali digunakan sebagai kurir dalam peredaran narkoba, bahkan ada yang sampai menjadi pemakai, dengan dijanjikan uang anak jadi tergiur akan uang yang dijanjikan oleh pengedar atau jasa pengantaran paket. Pada putusan Nomor : 25/Pid.Sus-Anak/PN Amb terjadi pada 2 anak yang kedapatan menjadi kurir dan menjadi pemakai untuk sebuah paket berisi Narkotika Gol I jenis tembakau sintesis (sinte) yang bernama Dewa Zeus.

\section{Pembahasan}

Hukum Pidana tidak boleh digunakan untuk alat penekananan terdapat pelaku tindak pidana namun Hukum Pidana juga harus dapat melindungi korban. ${ }^{5}$ Anak adalah sebagai generasi penerus/muda yang merupakan potensi dan penerus cita-cita perjuangan bangsa. Anak adalah merupakan modal dasar pembangunan yang memelihara, mempertahankan, dan mengembangkan hasil pembangunan yang akan datang bahkan yang sudah ada saat ini. Oleh karena itu anak memerlukan Perlindungan dalam rangka menjamin pertumbuhan dan perkembangan fisik, mental, dan sosial secara utuh, serasi dan seimbang ${ }^{6}$

\section{${ }^{3}$ Ibid}

${ }^{4}$ Lokollo, L., Salamor, Y., \& Ubwarin, E. (2020). Kebijakan Formulasi Undang-undang Narkotika Dalam Legalisasi Penggunaan Ganja Sebagai Bahan Pengobatan di Indonesia. JURNAL BELO, 5(2), 1-20. https://doi.org/10.30598/belovol5issue2page1-20

5 Erwin Ubwarin, Deassy Jacomina Anthoneta Hehanussa, Jetty Martje Patty, \& Anna Maria Salamor, (2021). Kekebalan Hukum Pidana dalam Penanganan Bencana Non-Alam Akibat Sars-Cov-2.

Jurnal Penelitian Hukum De Jure, $\quad$ Volume $21 \quad$ Nomor 1.
DOI: http://dx.doi.org/10.30641/dejure.2021.V21.13-22

${ }^{6}$ Darwan Prist, Hukum Anak Indonesia, PT. Citra Aditya Bakti, Bandung, 1997 hal. 2 
Pemidanaan terhadap anak yang berkonflik dengan hukum pasca berlakunya Undang-Undang Nomor 11 Tahun 2012 tentang Sistem Peradilan Pidana Anak, yaitu: (1) Anak yang belum berumur 12 (dua belas) tahun (sesuai Pasal 21 UU SPPA) yaitu: diserahkan kembali ke orang tua/wali dan diikutsertakan dalam pendidikan dan pembimbingan LPKS. (2) Anak yang berumur 12 (dua belas) tahun sampai dengan 14 (empat belas) tahun (sesuai Pasal 82 UU SPPA) berupa tindakan, yaitu: dikembalikan ke orang tua/wali dan perawatan di LPKS. (3) Anak yang berumur 15 (lima belas) tahun sampai dengan 18 (delapan belas) tahun (sesuai Pasal 71 UU SPPA) yaitu: pidana pokok, terdiri dari: pidana peringatan, pidana bersyarat, pelatihan kerja, pembinaan dalam lembaga dan penjara. Selain pidana pokok juga ada pidana tambahan, yaitu: dikembalikan ke orang tua dan ikut dalam pelatihan di LPKS. ${ }^{7}$

Pertimbangan Hakim dalam menjatuhkan pidana tidak selalu mengacu pada undang-undang, karena Hakim mempunyai pertimbangan tersendiri terkait dengan perkara yang ditanganinya, misalnya: (a) Sifat dari perbuatan pidananya itu sendiri, contohnya apakah lalai, sengaja, keji, berulang atau perbarengan, dan lain-lain; (b) adanya perdamaian antara pelaku dan korban (c) nilai kerugian; (d) sisi korban; (e) usia korban dan pelaku anak; dan (f) itikad untuk memperbaiki diri dari pelaku. Saat ini keadaan berkembang seiring dengan konsep berpikir manusia yang juga berkembang sehingga apabila seorang anak melakukan tindak pidana dalam hal proses yang diberlakukan terhadap seorang anak hendaknya lebih menekankan sarana non-penal yang dapat diambil namun haruslah tetap berorientasi dengan koridor hukum yang berlaku sehingga sarana non-penal dapat diterapkan pada kasus-kasus tertentu dengan syarat tertentu pula serta adanya peningkatan sumber daya manusia dari aparatur penegak hukum sehingga proses penanganan anak yang

${ }^{7}$ Michael Last Yuliar Syamriyadi Nugroho. PERLINDUNGAN HUKUM TERHADAP ANAK YANG BERKONFLIK DENGAN HUKUM DALAM PROSES PERSIDANGAN DI PENGADILAN NEGERI, Program Pasca Sarjana Magister Hukum Universitas Muhammadiyah Surakarta. 2016

DOI: https://doi.org/10.30598/belovol6issue1page195-207 
bermasalah dengan hukum sesuai dengan instrumen internasional dan hukum positif di Indonesia demi masa depan anak yang lebih baik. ${ }^{8}$

Paulus Hadisuprapto yang meyebutkan bahwa penjatuhan pidana terhadap anak sebagai pelaku tindak pidana cenderung merugikan perkembangan jiwa anak di masa yang akan datang. Kecenderungan merugikan ini akibat dari efek penjatuhan pidana terutama pidana penjara yang berupa stigma atau cap jahat pada diri anak.8 Pendapat yang sama juga diutarakan oleh Barda Nawawi Arief yang menyebutkan bahwa pidana penjara dapat memberikan stigma yang akan terbawa terus meskipun anak yang melakukan tindak pidana tersebut tidak melakukan kejahatan lagi. Akibat penerapan stigma bagi anak akan membuat mereka sulit untuk kembali menjadi anak "baik".

Pada putusan Nomor: 25/Pid.Sus-Anak/PN Amb terjadi pada 2 anak yang kedapatan menjadi kurir untuk sebuah paket berisi Narkotika Gol I jenis tembakau sintesis (sinte) yang bernama Dewa Zeus. Kronologinya sebagai berikut; Seorang anak bernama Srimaharaja Wattimury Sangadji alias Raja mengajak temannya yang bernama Gilang Saputra Adriansz alias Gilang untuk ditemani ke sebuah jasa pengiriman J\&T cabang Ambon via chat WhatsApp dengan isi pesan "Besok batamang beta ka J\&T dolo par angka paket." kemudian dibalas oleh Gilang "Iyo nanti kalau mau pergi wa beta saja."

Petugas Polisi BNNP pada tanggal 09 juli 2020 telah mendapat informasi tentang paket dari Makasar yang telah dicurigai, informasi ini didapat dari BEA CUKAI. Keesokannya hari Jumat tanggal 10 juli 2020 sekitar pukul 11.30 WIT di J\&T cabang Ambon Unit Kebun Cengkeh, kecamatanSirimau, kota Ambon, datang kedua remaja tersebut. Awalnya Raja yang menanyakan paket dengan nomor resi pengiriman: JD 0079416615, namun Raja merasa kawathir dan langsung keluar tanpa mengambil paket tersebut. Raja lalu meminta Gilang untuk masuk dan mengambil paket tersebut, Gilang lalu

\footnotetext{
${ }^{8}$ Paulus Hadisaputro. Juvenile Delinguency. Bandung: Citra Aditya Bakti. 2003, hal. 124

9 Barda Nawawi Arief. 1994. Kebijakan Legislatif Dalam Penanggulangan Kejahatan Dengan Pidana Penjara. Semarang: Ananta. Hal. 47.
}

DOI: https://doi.org/10.30598/belovol6issue1page195-207 
masuk dan mengambil paket yang telah dicurigai. Tanpa lama-lama, Gilang langsung diciduk oleh Polisi BNNP yang bertugas (Victor Rawulunubun dan Thomas Uniwally). Kemudian Gilang langsung dibawa ke Kantor Bea Cukai Ambon untul membuka paket tersebut. Raja yang melihat temannya disergap tanpa lama langsung melarikan diri.

Setelah dari kantor Bea Cukai Ambon, petugas Polisi BNNP, Victor Rawulunubun dan Thomas Uniwally melakukan pengembangan untuk mencari anak Raja yang telah melarikan diri. Pada pukul 15.00 WIT,polisi BNNP bertugas berhasil menemukan Raja di lorong SMP 14 yang berjarak kira-kira 300 meter dari kantor J\&T Kebun Cengkeh. Setelah dilakukan interogasi,anak Gilang mengaku ia hanya diminta menemani untuk mengambil paket, sedangkan anak Raja mengakui disuruh oleh seseorang dengan nama Irsan Litiloly atau Irsan Frahadi alias ZARKO yang namanya tertera pada paket kiriman tersebut, kini ZARKO menjadi DPO (Daftar Pencarian Orang).

Barang bukti yang telah diamankan berupa :

1. 1 (satu) paket kiriman asal Makasar dengan nomor resi : JD0079416615 yang berisikan Narkotika Gol 1 jenis tembakau sintesis yang bernama Dewa Zeus.

2. 1 (satu) buah handphone warna hitam merkVivo 1820 bernomor simpati 082239538243

3. 1 (satu) buah handphonewrna hitam merkVivo 1901 bernomor simpati 08523169009

Dilakukan juga pengujian laboratorium No. 1BS.02/VII/2020/Pusat Lab Narkotika tanggal 14 Juli 2020 yang ditanda tangani oleh Dila Rachma Aryaningrum, S.Farm dan Novembry Nimas Sakti, A.Md.Si, bahwa barang bukti berupa 1 (satu) bungkus plastik bening yang didalamnya terdapat Golden Zeus V2 berisi bahan daun dengan berat 3,3643 gram mengandung 5F-MDMB-PICA/5F-MDMB-2201 : Metil 2 \{\{1-(5Flouropentil\}indol-3-kaboni\}animo\}-3-3 dimetilbutanoat, yang dimana terdaftar dalam Golongan 1 Narkotika Daftar Nomor 166, Peraturan Mentri Kesehatan Republik Indonesia 
Nomor 5 Tahun 2020 tentang Perubahan Penggolongan Narkotika didalam lampiran Undang-Undang Nomor 35 Tahun 2009 tentang Narkotika dan mengandung 4-flouro MDMB-BINACA-4 flouro MDMB-BUTUNACA : Metil yang termasuk dalam Golongan I Narkotika Daftar Nomor 177 Peraturan Menteri Kesehatan Republik Indonesia Nomor 5 tahun 2020 tentang Perubahan Penggolongan Narkotika dalam lampiran Undang-Undang Nomor 35 Tahun 2009. Majelis Hakim dengan ini memutuskan: Menyatakan bahwa Terdakwa I Gilang Putra Adriansz alias Gilang dan Terdakwa II Srimaharaja Wattimury Sangadji alias Raja terbukti secara sah bersalah 'Penyalahgunaan Narkotika untuk diri sendiri' yang sebagaimana melanggar pasal 127 ayat (1) huruf A Undang-Undang Nomor 35 tahun 2009 tentang Narkotika.

Menjatuhkan pidana terhadap Terdakwa I Gilang Putra Adriansz alias Gilang dan Terdakwa II Srimaharaja Wattimury Sangadji alias Raja dengan Pidana Pembinaan Dalam Lembaga LPKS Panti Sosial Bina Remaja dan Anak Berhadapan Dengan Hukum (PSBR) Hiti-Hiti Hala-Hala selama 9 bulan.

Menyatakan barang bukti berupa :

1. 1 (satu) paket kiriman asal Makasar dengan nomor resi : JD0079416615 yang berisikan Narkotika Gol 1 jenis tembakau sintesis yang bernama Dewa Zeus.

2. 1 (satu) buah handphone warna hitam merk Vivo 1820 bernomor Simpati 082239538xxx

3. 1 (satu) buah handphone warna hitam merk Vivo 1901 bernomor simpati 08523169xxx

Yang dirampas untuk dimusnahkan membebankan kepada Terdakwa I Gilang Putra Adriansz alias Gilang dan Terdakwa II Srimaharaja Wattimury Sangadji alias Raja untuk membayar biaya perkara sebesar Rp. 2000,00 (dua ribu rupiah) 
Fakta persidangan dalam Putusan Nomor 25/Pid.Sus-Anak/2020/PN Amb, Terdakwa I dan Terdakwa dua mengakui bawah mereka sudah dua kali memakai Narkoba secara berasama-sama yaitu pada bulan November 2019 dan sekitar bulan Juni 2020, 1 buah paket yang mereka pakai biasanya dicampur dengan rokok Malboro yang dibuat dalam 3 (tiga) linting. Menurut penulis ada yang ganjil dalam putusan ini, kenapa penulis mengatakan bahwa ada ganjil dalam tulisakan ini karena:

a. Undang-Undang Nomor 35 Tahun 2009 tentang Narkotika, Pasal 54 menyatakan pecandu narkotika dan korban penyalahgunaan narkotika wajib menjalani rehabilitasi medis dan sosial. Rehabilitasi medis yakni terkait pengobatan dan pemulihan kesehatan. Sedangkan rehabilitasi sosial terkait pemulihan sosial dan mental pecandu narkoba.

b. Pasal 55 menyebutkan permohonan rehabilitasi ini dilaporkan oleh si pecandu atau keluarga ke lembaga rehabilitasi medis dan sosial. Sedangkan untuk pecandu narkoba di bawah umur, dilaporkan oleh walinya.

c. Pasal 103 UU Narkotika menyebutkan:

(1) Hakim yang memeriksa perkara Pecandu Narkotika dapat:

a. memutus untuk memerintahkan yang bersangkutan menjalani pengobatan dan/atau perawatan melalui rehabilitasi jika Pecandu Narkotika tersebut terbukti bersalah melakukan tindak pidana Narkotika; atau.

b. menetapkan untuk memerintahkan yang bersangkutan menjalani pengobatan dan/atau perawatan melalui rehabilitasi jika Pecandu Narkotika tersebut tidak terbukti bersalah melakukan tindak pidana Narkotika.

(2) Masa menjalani pengobatan dan/atau perawatan bagi Pecandu Narkotika sebagaimana dimaksud pada ayat (1) huruf a diperhitungkan sebagai masa menjalani hukuman.

Walaupun dalam fakta persidangan juga muncul bahwa anak ini sebagai kurir, kita tidak boleh melupakan hak-haknya, Hak anak adalah hak dasar yang wajib diberikan dan didapatkan oleh anak meliputi anak usia dini dan juga remaja usia 12-18 tahun. Hak anak ini berlaku baik anak yang mempunyai orang tua ataupun sudah tidak mempunyai orang tua, dan juga anak-anak terlantar.Hak anak menjadi sesuatu yang sudah selayaknya 
didapatkan oleh anak. Menurut KHA (Konvensi Hak Anak) yang diratifikasi kedalam Kepres No 36 Tahun 1997, terdapat 10 Hak Mutlak Anak: ${ }^{10}$

1. Hak Gembira Setiap anak berhak atas rasa gembira, dan kebahagiaan seorang anak itu harus dipenuhi.

2. Hak Pendidikan Setiap anak berhak memperoleh pendidikan yang layak.

3. Hak Perlindungan Setiap anak berhak mendapatkan perlindungan, dilindungi dari segala tindak kekerasan dan penganiayaan.

4. Hak Untuk memperoleh Nama Setiap Anak berhak memperoleh nama, sebagai salah satu identitas anak.

5. Hak atas Kebangsaan Setiap anak berhak diakui sebagai warga negara dan memiliki kebangsaan, anak tidak boleh apatride (tanpa kebanngsaan).

6. Hak Makanan Setiap anak berhak memperoleh makanan untuk tumbuh kembang dan mempertahankan hidupnya.

7. Hak Kesehatan Setiap anak berhak memperoleh pelayanan kesehatan yang layak, tanpa diskriminasi, anak harus dilayani dalam kesehatan.

8. Hak Rekreasi Setiap anak berhak untuk rekreasi untuk refreshing, dan anak harus dilibatkan dalam memilih tempat rekreasi yang mereka inginkan.

9. Hak Kesamaan Setiap anak berhak diperlakukan sama dimanapun dan kapanpun, tanpa ada tindak diskriminasi.

10. Hak Peran dalam Pembangunan Setiap anak berhak dilibatkan dalam pembangunan negara, karena anak adalah masa depan bangsa.

Sedangkan untuk hak dasar anak, terdapat 4 hak dasar anak, yaitu: ${ }^{11}$

1. Hak Hidup

Hak hidup ini berlaku dari semenjak anak itu masih dalam kandungan, yang termasuk kedalam hak hidup adalah seperti memberikan gizi dan rangsanganrangsangan ketika anak masih dalam kandungan, periksa kandungan, dan lain- lain.

2. Hak Tumbuh Kembang

Dalam kehidupan anak, anak harus diberikan kesempatan sebaik-baiknya untuk tumbuh dan berkembang, seperti mendapatan pengasuhan, pendidikan yang baik, jika sakit diobati atau dibawa kedokter, diberi ASI,di imunisasi, dibawa ke posyandu.Selain itu perkembangan Psikisnya pun diperhatikan, seperti

${ }^{10}$ Anissa Nur Fitri, Agus Wahyudi Riana, \& Muhammad Fedryansyah, PERLINDUNGAN HAKHAK ANAK DALAM UPAYA PENINGKATAN KESEJAHTERAAN ANAK, PROSIDING KS: RISET \& PKM, Volume 2 Nomor 1, hal 45-50

${ }^{11}$ Ibid

DOI: https://doi.org/10.30598/belovol6issue1page195-207 
memberikan rasa aman dan rasa nyaman, membuat lingkungan kondusif, menjauhkan anak dari hal-hal yang berbahaya, tidak memberikan makanan yang berbahaya bagi perkembangannya.

3. Hak Partisipasi

Maksud dari hak partisipasi disini adalah anak harus dilindungi dari situasi-situasi darurat, menerapkan tentang perlindungan hukum, dan dari apapun yang berkaitan dengan masa depan si anak.

4. Hak Perlindungan

Anak mempunyai hak untuk mendapatkan perlindungan dan menentukan pilihan untuk hidupnya. Anak dalam keluarga harus dibiasakan berbicara, agar anak mempunyai hak suara dan mulai berani menentukan hal-hal yang diinginkan. Contohnya adalah ingin saat anak memiliki keinginan yang berbeda dengan keinginan orangtuanya, maka dicarikan titik temu. Hal ini perlu diperhatikan karena apa yang ditentukan oleh orang dewasa itu belum tentu baik pula bagi si anak, sehingga anak juga diperlakukan sebagai insan yang dimanusiakan.

Untuk itu dalam kasus diatas harusnya anak diberikan perlindungan hukum dengan memberikan rehabilitasi kedua anak tersebut pada tempat rehabilitasi narkotika yang telah ditunjuk oleh Negara. Kenapa mereka harus direhabitasi karena anak masih punya masa depan yang panjang, dan penangganannya berbeda dengan orang dewasa. Orang dewasa saja diberikan rehabilitasi, kenapa anak tidak maka wajib diberikan rehabilitasi.

\section{Penutup}

Anak adalah aset bangsa, karena aset bangsa maka anak harus dilindungi hakhaknya baik dalam perlindungan sosial maupun perlindungan hukum, anak yang sudah menjadi pemakai atau pecandu harus harus diberikan rehabilitasi, apalagi anak yang menjadi pecandu, wajib diberikan rehabilitasi, namun dalam Putusan Nomor 25/Pid.SusAnak/2020/PN Amb, anak ditempatkan bukan pada lembaga rehabilitasi, untuk itu harus dilakukan upaya hukum atas putusan tersebut agar hakim Pengadilan Tinggi dapat menetapkan dalam amar putusan agar kedua anak pelaku tindak pidana narkotika ditempatkan pada lembaga rehabilitasi yang ditunjuk sesuai dengan Pasal 103 UndangUndang Narkotika. 


\section{Daftar Pustaka}

\section{Jurnal}

[1] Lokollo, L., Salamor, Y. B., \& Ubwarin, E. (2020). Kebijakan Formulasi Undangundang Narkotika Dalam Legalisasi Penggunaan Ganja Sebagai BahanPengobatan di Indonesia. Jurnal Belo, Volume 5 Nomor 2. DOI: https://doi.org/10.30598/belovol5issue2page1-20

[2] Satino, Sulastri, \& Yuli W, Y. (2020). Perlindungan Hukum Terhadap Anak Yang Melakukan Tindak Pidana Melalui Diversi Berdasarkan Sistem Peradilan Pidana Anak. Esensi Hukum, 2(1), $15-27$.

DOI https://doi.org/10.35586/esensihukum.v2i1.26

[3] Erwin Ubwarin, Deassy Jacomina Anthoneta Hehanussa, Jetty Martje Patty, \& Anna Maria Salamor, (2021). Kekebalan Hukum Pidana dalam Penanganan Bencana Non-Alam Akibat Sars-Cov-2. Jurnal Penelitian Hukum De Jure, Volume 21 Nomor 1. DOI: http://dx.doi.org/10.30641/dejure.2021.V21.13-22

[4] Anissa Nur Fitri, Agus Wahyudi Riana, \& Muhammad Fedryansyah, PERLINDUNGAN HAK-HAK ANAK DALAM UPAYA PENINGKATAN KESEJAHTERAAN ANAK, PROSIDING KS: RISET \& PKM, Volume 2 Nomor 1, hal 45-50

\section{Buku}

[5] Barda Nawawi Arief. 1994. Kebijakan Legislatif Dalam Penanggulangan Kejahatan Dengan Pidana Penjara. Semarang: Ananta.

[6] Darwan Prist, 1997, Hukum Anak Indonesia, PT. Citra Aditya Bakti, Bandung.

[7] Michael Last Yuliar Syamriyadi Nugroho. PERLINDUNGAN HUKUM TERHADAP ANAK YANG BERKONFLIK DENGAN HUKUM DALAM PROSES PERSIDANGAN DI PENGADILAN NEGERI, Program Pasca Sarjana Magister Hukum Universitas Muhammadiyah Surakarta. 2016

[8] Paulus Hadisaputro. 2003 Juvenile Delinguency. Bandung: Citra Aditya Bakti. 
Jacob Hattu, Astuti Nur Fadillah, Perlindungan Anak.............

p-ISSN : 2460-6820 | e-ISSN : 2686-5920 Jurnal Belo Vol. 6 No. 2 Februari 2021 - Juli 2021 | 207

[9] Romli Atmasasmita, 1997, Peradilan Anak di Indonesia, Bandung: Mandar Maju. 